\title{
Effect of Cold Pressor Test (CPT) on Pulse Rate and Blood Pressure amongst Individuals with and without Family History of Hypertension
}

\author{
Sanjay S. Pandarbale ${ }^{1}$, Yogesh P. Nerkar², Sufala R. Malnekar³
}

${ }^{1}$ Department of Physiology, Goa Medical College, Bambolim, Goa, India. ${ }^{2}$ Department of Physiology, Goa Medical College, Bambolim, Goa, India. ${ }^{3}$ Department of Physiology, Goa Medical College, Bambolim, Goa, India.

\section{ABSTRACT}

\section{BACKGROUND}

It is an established fact that primary and secondary hypertension and related cardiovascular disorders have a familial predisposition. We also know that essential hypertension is the most common amongst hypertensives. The aim of our study was to find out effect of cold pressor test (CPT) on heart rate and blood pressure amongst individuals with and without family history of hypertension.

\section{METHODS}

Present study was undertaken using within group design consisting of measurements at basal and CPT and the parameters studied were pulse rate and Blood pressure.

\section{RESULTS}

In our study we found that in males with family history of HT $(n=15)$, the mean basal pulse rate was 78.33 beats/min and following CPT it increased to 85.73. Similarly, in males without family history of HT $(n=18)$ mean basal pulse rate was 77.28 beats/min and following CPT it increased to 86.72 beats/min. In both cases it was statistically significant. But it is observed that in case of females with family history of HT $(n=20)$ mean basal pulse rate was 80.9 beats/min and following CPT it increased to 89.1. Similarly, in Females without family history of HT $(n=26)$ mean basal pulse rate was 77.15 beats/min and following CPT it increased to 84.73 beats/min and in both these cases, it was statistically significant. In males with family history of HT ( $\mathrm{n}=15)$, mean basal SBP was $115.13 \mathrm{mmHg}$ and following CPT increased to 123.93 and this was statistically significant and the mean DBP was $74.67 \mathrm{mmHg}$ and following CPT it increased to $79.82 \mathrm{mmHg}$ and it was not statistically significant. In males without family history of HT $(n=18)$ mean basal SBP was $114.67 \mathrm{mmHg}$ and following CPT it was increased to $122.89 \mathrm{mmHg}$ and increase was statistically significant and mean DBP was $74.44 \mathrm{mmHg}$ and following CPT it increased to $76.33 \mathrm{mmHg}$ and this increase was not statistically significant. In females with family with family history of HT $(n=20)$ the mean SBP was 114.2 $\mathrm{mmHg}$ and following CPT it increased to $121.9 \mathrm{mmHg}$ and it was statistically significant and the mean DBP was $73.75 \mathrm{mmHg}$ and following CPT it increased to $78.80 \mathrm{mmHg}$ and it was not statistically significant. In females without family history of HT $(n=26)$ the mean basal SBP was $108.23 \mathrm{mmHg}$ and following CPT it increased to $117.08 \mathrm{mmHg}$ and the mean basal DBP was $69.92 \mathrm{mmHg}$ and following CPT it was increased to $76.69 \mathrm{mmHg}$ this increase in both the cases was statistically significant (table 1,2). In both the groups, none of the subjects was found to be hyperreactive to either systolic or diastolic blood pressure when they were subjected to CPT.

\section{CONCLUSIONS}

In both the groups, subjects were found to be hyporeactive or normoreactive to either systolic or diastolic blood pressure when they were subjected to CPT. But increase in basal blood pressure response is known to be due to CPT.

\section{KEY WORDS}

CPT, SBP, DBP, Hyperreactive, Hyporeactive, Hand Immersion in Cold Water at 10 ${ }^{0} \mathrm{C}$
Corresponding Author: Dr. Sanjay S. Pandarbale, Associate Professor, Department of Physiology, Goa Medical College, Bambolim, Goa, India. E-mail: drsanjayspandarbale@gmail.com

DOI: $10.14260 /$ jemds/2020/488

How to Cite This Article:

Pandarbale SS, Nerkar YP, Malnekar SR Effect of cold pressor test (CPT) on pulse rate and blood pressure amongst individuals with and without family history of hypertension. J. Evolution Med. Dent. Sci. 2020;9(32):2253-2256,

$10.14260 /$ jemds $/ 2020 / 488$

Submission 09-05-2020,

Peer Review 01-07-2020,

Acceptance 09-07-2020,

Published 10-08-2020.

Copyright (C) 2020 JEMDS. This is an open access article distributed under Creative Commons Attribution License [Attribution 4.0 International (CC BY 4.0)] 


\section{BACKGROUND}

In this world, we wrestle with various pressures of life. But in this stressful life, all of us prone to suffer from hypertension one day or other. Essential hypertension is the commonest one which we encounter. At present it is treatable but not curable, it is polygenic in origin and many environmental factors play a role in this. ${ }^{1}$ It is now an established fact that primary and secondary hypertension and related cardiovascular disorders have a familial predisposition. We also know that essential hypertension is the most common amongst hypertensives. Studies have shown that sympathetic nervous system plays a major role in the pathogenesis of essential hypertension in the individual. And in individuals with positive family history of hypertension have shown blood pressure hyper-responsiveness to stressful stimuli which is mediated by increased activity of the sympathetic nervous system. ${ }^{2}$ It is known that BP in the individual can be affected by the temperature and many other stressors. ${ }^{3,4}$ It is known that CPT can be used as a method to predict reactivity of BP to external stimulus and for predicting susceptibility of an individual to hypertension. 4,5 The aim of our study was to find out effect of cold pressor test (CPT) on pulse rate and blood pressure amongst individuals with and without family history of hypertension.

\section{METHODS}

Present study was undertaken using before and after experimental study/interventional study design consisting of measurements at basal and CPT and the parameters studied were pulse rate and blood pressure. For convenience, we took 79 apparently healthy asymptomatic normotensive medical students of either sex ( $n=33$ males and $n=46$ females) in the age group of 17 to 20 years. Males were further divided into ( $n=15$ with family history of HT, and $n=18$ without family history of HT), and females were divided into ( $\mathrm{n}=20$ with family history of HT and $n=26$ without family history of HT) and they were subjected to Cold pressor test (CPT) to assess their Cardiovascular reactivity. CPT was carried out by immersing subjects left hand up to wrist joint for maximum of 30 seconds or till the subject could bear, in cold water mixed with ice cubes kept in the thermocol box, so the temperature is maintained at $10{ }^{\circ} \mathrm{C}$ and pulse rate and $\mathrm{BP}$ was recorded from right hand. 6 Data was collected and analysed using paired $t$ test and paired differences were calculated using 95\% confidence interval of the difference and $p$ value of $<0.05$ was taken as scientifically significant.

\section{Inclusion Criteria}

Apparently Healthy, willingness to participate in the study.

\section{Exclusion Criteria}

Subjects involved in physical exercise, yoga, pranayama, smoking, consumption of alcohol 24 hours before participating in the study, on medications like antihypertensives, analgesics, sedatives, suffering from any cardiorespiratory disorders.

\section{RESULTS}

In our study we found that in the case of both males and females with and without family history of hypertension the mean basal pulse rate following CPT was increased and this increase was statistically significant in both the cases. In the case of males with family history of hypertension the mean basal and following CPT both SBP and DBP increased and in case of SBP this increase was statistically significant and in the case of DBP this increase was not statistically significant. But in the case of females with family history of hypertension the mean basal and following CPT both SBP and DBP increased and increase in case of SBP it was statistically significant but increase in case of DBP was not statistically significant.

And in case of males without family history of hypertension the mean basal and following CPT both SBP and DBP increased and increase in case of SBP was statistically significant whereas increase in case of DBP was not statistically significant. In case of females without family history of hypertension the mean basal and following CPT and both SBP and DBP increased and increase in both this cases was statistically significant. In both the groups subjects were found to be hyporeactive or normoreactive to either systolic or diastolic blood pressure when they were subjected to CPT (table 1, 2).

\begin{tabular}{|c|c|c|c|c|c|c|c|c|c|c|c|c|}
\hline$\stackrel{\Sigma}{\Sigma}$ & $\frac{0}{n^{2}}$ & $\underset{\sum}{\frac{0}{\pi}}$ & $\frac{0}{\Sigma}$ & $\frac{0}{\tilde{\pi}}$ & $\frac{0}{\Sigma}$ & $\frac{0}{\sum}$ & 䒕 & 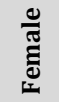 & 迩 & 营 & ฏ & 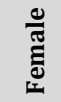 \\
\hline Condition & Basal & СРT & Basal & CPT & Basal & СРT & Basal & СРT & Basal & l CPT & Basal & CPT \\
\hline Parameter & Pulse & Pulse & SBP & SBP & DBP & DBP & Pulse & Pulse & SBP & SBP & DBP & DBP \\
\hline $\mathrm{N}$ & 15 & 15 & 15 & 15 & 15 & 15 & 20 & 20 & 20 & 20 & 20 & 20 \\
\hline $\mathrm{F} / \mathrm{H}$ & + & + & + & + & + & + & + & + & + & + & + & + \\
\hline Mean & 78.338 & 85.73 & 115.13 & 123.93 & 374.67 & 79.82 & 80.9 & 89.1 & 114.2 & 2121.9 & 73.75 & 78.8 \\
\hline $\mathrm{SD} \pm$ & 6.16 & 6.45 & 10.84 & 9.36 & 7.88 & 8.02 & 5.9 & 6.98 & 5.5 & 13.26 & 7.55 & 13.34 \\
\hline Df & \multicolumn{2}{|c|}{14} & \multicolumn{2}{|c|}{14} & \multicolumn{2}{|c|}{14} & \multicolumn{2}{|c|}{19} & \multicolumn{2}{|c|}{19} & \multicolumn{2}{|c|}{19} \\
\hline$t$ & \multicolumn{2}{|c|}{4.4239} & \multicolumn{2}{|c|}{4.6045} & \multicolumn{2}{|c|}{2.0817} & \multicolumn{2}{|c|}{4.5372} & \multicolumn{2}{|c|}{2.5734} & \multicolumn{2}{|c|}{1.9646} \\
\hline & \multicolumn{2}{|c|}{0.0006} & \multicolumn{2}{|c|}{0.0012} & \multicolumn{2}{|c|}{0.0562} & \multicolumn{2}{|c|}{0.0002} & \multicolumn{2}{|c|}{0.0186} & \multicolumn{2}{|c|}{0.0643} \\
\hline $\mathrm{P}$ & \multicolumn{2}{|c|}{ ES } & \multicolumn{2}{|c|}{ VS } & \multicolumn{2}{|c|}{ NS } & \multicolumn{2}{|c|}{ ES } & \multicolumn{2}{|r|}{$\mathrm{S}$} & \multicolumn{2}{|c|}{ NS } \\
\hline
\end{tabular}

Table 1. Basal Pulse Rate, SBP and DBP and the Same Following CPT in Males and Females with Family History of Hypertension

\begin{tabular}{|c|c|c|c|c|c|c|c|c|c|c|c|c|}
\hline & $\frac{0}{\pi^{\pi}}$ & $\sum^{\frac{0}{\pi}}$ & $\sum^{\frac{0}{\pi}}$ & $\frac{0}{\Sigma^{\pi}}$ & $\frac{0}{\sum^{\pi}}$ & $\frac{\varrho}{\tilde{\pi}^{\pi}}$ & 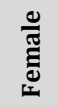 & ฮั & 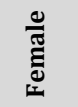 & 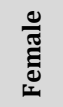 & 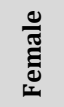 & 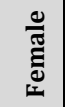 \\
\hline Condition & Basal & CPT & Basal & $\mathrm{CPT}$ & Basal & CPT & Basal & CPT & Basal & CPT & Basal & $1 \mathrm{CPT}$ \\
\hline Parameter & Pulse & Pulse & SBP & SBP & DBP & DBP & Pulse & Pulse & SBP & SBO & DBP & DBP \\
\hline $\mathrm{N}$ & 18 & 18 & 18 & 18 & 18 & 18 & 26 & 26 & 26 & 26 & 26 & 26 \\
\hline $\mathrm{F} / \mathrm{H}$ & --- & --- & --- & --- & -- & --- & --- & -- & --. & -- & --. & - \\
\hline Mean & 77.28 & 86.72 & 115.6 & 122.89 & 74.44 & 76.33 & 377.15 & 84.73 & 108.231 & 117.08 & 369.92 & 276.69 \\
\hline $\mathrm{SD} \pm$ & 7.37 & 12.63 & 10.06 & 7.66 & 8.99 & 6.59 & 6.03 & 7.24 & 10.12 & 10.71 & 5.59 & 8.25 \\
\hline $\mathrm{dF}$ & & 17 & & 7 & 1 & 7 & 1 & 9 & 25 & 5 & & 25 \\
\hline $\mathrm{T}$ & 2.49 & 956 & & 083 & 092 & 251 & 4.5 & 372 & 5.96 & 67 & & 8531 \\
\hline $\mathrm{P}$ & 0.02 & 232 & & 001 & 0.36 & 679 & 0.0 & 002 & 0.00 & 001 & & 0001 \\
\hline Significance & $\mathrm{s}$ & S & & S & $\mathrm{N}$ & IS & E & $S$ & ES & S & & ES \\
\hline
\end{tabular}




\section{DISCUSSION}

In our study we found that in the case of both males and females with and without family history of hypertension the mean basal pulse rate following CPT was increased and this increase was statistically significant in both the cases respectively. It is observed that in the case of males with family history of hypertension the mean basal blood pressure and following CPT both SBP and DBP increased and in case of SBP this increase was statistically significant and in the case of DBP this increase was not statistically significant. But in the case of females with family history of hypertension the mean basal blood pressure and following CPT both SBP and DBP increased and increase in case of SBP it was statistically significant but increase in case of DBP was not statistically significant. And in case of males without family history of hypertension the mean basal blood pressure and following CPT both SBP and DBP increased and increase in case of SBP was statistically significant whereas increase in case of DBP was not statistically significant. In case of females without family history of hypertension the mean basal blood pressure and following CPT and both SBP and DBP increased and increase in both this cases was statistically significant respectively. In both the groups of our study, subjects were found to be hyporeactive or normoreactive to either systolic or diastolic blood pressure when they were subjected to CPT. But increase in basal blood pressure response is known to be due to CPT.

The criteria for systolic and diastolic hyper reactors as per Hines et al is that when SBP and DBP increases more than $20 \mathrm{mmHg}$ and $15 \mathrm{mmHg}$ respectively. Following CPT there is rise in pulse rate this could be attributed to Stressor, like immersion of hand in cold water at $10^{\circ} \mathrm{C}$ causes cold sensation and pain. Also there is stimulation of sympathetic noradrenergic fibers which leads to vasoconstriction. Sympathetic nerves contains NPY, which causes vasoconstriction and activation of sympathetic nerves leads to increase in heart rate and blood pressure. CPT increases heart rate and both SBP and DBP as there is increase vascular resistance and increase in muscular sympathetic activity which is mediated by autonomic neural pathways. Also temperature is known to affect pulse rate and blood pressure in the individual. In both subjects with family history of hypertension they had high resting pulse and SBP and DBP compared to their counterparts. 7,8

In our study there is no statistically significant difference in pulse and both SBP and DBP in males with family history of hypertension and our studies are in consensus with studies done by Verma et al. ${ }^{9}$ But in case of males with and without family history of HT DBP was statistically significant. And in the case of females with and without family history of HT basal pulse and following CPT showed statistically significance. This gender difference could be because of difference in pain threshold and reactivity to pain which in turn could lead to rise in pulse rate and BP. ${ }^{10}$ As per study carried out by Marie-Helene, Roy- Gagnon et al showed that $\mathrm{BP}$ response to $\mathrm{CPT}$ is heritable and genetic factors influence reactivity to $\mathrm{BP}$ and recovery. Those who exhibit hyper reaction on hand immersion at $10^{\circ} \mathrm{C}$ may develop hypertension in later stages of life. CPT is a very simple, noninvasive and yet effective tool in monitoring vascular reactivity and development of hypertension in later stage in both the genders. ${ }^{4,11}$

In our study we found that in there was increase in pulse rate in males without family history of hypertension following CPT and this increase was more than that of with family history of hypertension. Similarly there was increase in pulse rate in females with family history of hypertension following CPT and this increase was more than that of without family history of hypertension. In males increase in both SBP and DBP following CPT was more with those having family history of hypertension than that compared to without family history of hypertension and $p$ value was significant for SBP but not significant for DBP. In females increase in SBP and DBP following CPT was more with family history of hypertension than when compared to without family history of hypertension and $\mathrm{p}$ value was significant for SBP and DBP in case of females without family history of hypertension and significant for SBP and not significant for DBP in case of family history of hypertension. Probable explanation for our findings could be that difference in pain threshold and pain reactivity between two groups of individuals which could cause increase in pulse rate, and rise in SBP and DBP in case of family history of hypertension. Also increase in pulse rate and rise in SBP in males and rise in DBP in females in case of without family history of hypertension reasons could be presence of more amount of oestrogen in females which has protective action on the vascular endothelium, also there is increase in $\mathrm{NO}$ and decrease in Endothelin production. And we have seen variable response of CPT in both the genders. CPT can be used for the diagnosis of hyperreactive or hyporeactive (normoreactive) subjects and future risk of suffering from hypertension in the individual can be identified.12, 13

\section{CONCLUSIONS}

In both the groups, subjects were found to be hyporeactive or normoreactive to either systolic or diastolic blood pressure when they were subjected to CPT. But increase in basal blood pressure response is known to be due to CPT. Blood pressure response to $\mathrm{CPT}$ is heritable and genetic factors influence reactivity to it. CPT is simple, convenient and non-invasive technique which can be used as a method to predict reactivity of blood pressure to external stimulus and for predicting susceptibility of an individual to hypertension in the near future and can be controlled at the earliest by life style modifications and by use of appropriate drugs, and thereby further complications arising from hypertension can be prevented.

Financial or Other Competing Interests: None.

\section{REFERENCES}

[1] Hulley SB, Cummings SR, Browner BS, et al. designing an experiment: Clinical trials I. Text book of Designing clinical research. $2^{\text {nd }}$ edn. Lippincott Williams and Wilkins Reprint 2001: p. 143-93. 
[2] Schmieder RE, Langewitz W, Otten $H$, et al. Psychophysiologic aspects in essential hypertension. J Hum Hypertens 1987; 1(3):215-22.

[3] Silverthorn DU, Michael J. Cold stress and the cold pressor test. Advances in Physiology Education 2013; 37(1):93-6.

[4] Sardessai SR, Pandarbale SS. Effect of cold pressor test on blood pressure in subjects with hypertensive first degree relatives. J Evolution Med Dent Sci 2017; 6(52):3963-6.

[5] Hines EA Jr, Brown GE. The cold pressor test for measuring the reactibility of the blood pressure: data concerning 571 normal and hypertensive subjects. Am Heart J 1936; 11(1):1-9.

[6] Jain AK. Manual of practical physiology for MBBS. $5^{\text {th }}$ edn. Arya Publications. Avichal Publishing Company, 2016: p. 130-2.

[7] Pramanik T, Regimi P, Adhikari P, et al. Cold pressor test as a predictor of hypertension. The Journal of Tehran University Heart Center 2009; 4(3):177-80.
[8] Barret KE, Boitano S, Barman SM, et al. Ganong's review of Medical Physiology. 25th edn. New Delhi: McGraw-Hill Education (India) Private Limited., 2016; p. 586.

[9] Verma V, Singh SK, Ghosh S. Identification of susceptibility to hypertension by the cold pressor test. Indian J Physiol Pharmacol 2005; 49(1):119-20.

[10] Shrivastava RD, Kumar M, Shinghal R, et al. Influence of age and gender on cold pressor response in Indian population. Indian J Physiol Pharmacol 2010; 54(2):1748.

[11] Roy-Gagnon MH, Weir MR, Sorkin JD, et al. Genetic influences on blood pressure response to the cold pressor test: results from HAPI Heart Study. J Hypertens 2008; 26(4):729-36.

[12] Mourot L, Bouhaddi M, Regnard J. Effects of the cold pressor test on cardiac autonomic control in normal subjects. Physiol Res 2009; 58(1):83-91.

[13] Mahalakshmamma V, Sukumar CD. Gender variations in cardiovascular responses to cold pressor test in normal subjects. Sch J App Med Sci 2016; 4(8C):2943-6. 